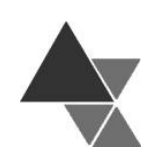

\title{
Como o consumo domiciliar de alimentos específicos varia com a renda, Brasil, 2017-2018
}

\author{
Rodolfo Hoffmann ${ }^{1}$ e Josimar Gonçalves de Jesus ${ }^{2}$
}

Utilizando os dados da Pesquisa de Orçamentos Familiares 2017-2018, são estimadas as elasticidades-renda do consumo domiciliar (em quilogramas per capita) para diversos tipos de frutas, hortaliças, leite, carnes etc. A metodologia consiste no ajuste, para cada alimento, de uma poligonal para a variação do logaritmo do consumo per capita em função do logaritmo da renda per capita, usando valores médios em dez classes de renda familiar per capita. Verifica-se, por exemplo, que a elasticidade-renda do consumo domiciliar é praticamente nula para arroz e feijão, é negativa para farinha de mandioca e que, como esperado, é maior para carne bovina de primeira $(0,613)$ do que para carne bovina de segunda $(0,204)$. Para produtos selecionados são analisadas as diferenças entre áreas urbanas e áreas rurais e entre as cinco grandes regiões do País.

Palavras-chave: Elasticidade-renda, consumo de alimentos.

\section{How household consumption of specific foods varies with income, Brazil, 2017-2018}

Using data from the Brazilian Household Budget Survey 2017-2018, the income elasticities of household consumption (in kilograms per capita) are estimated for various types of fruits, vegetables, milk, meat, etc. The methodology consists of adjusting, for each food, a polygonal for the variation of the logarithm of per capita consumption as a function of the logarithm of per capita income, using average values in ten classes of per capita family income. It is verified, for example, that the income elasticity of household consumption is practically zero for rice and beans, is negative for cassava flour and that, as expected, it is higher for first-rate beef (0.613) than for second-rate beef (0.204). For selected products, the differences between urban and rural areas and between the five major regions of the country are analysed.

Keywords: Income elasticities, food consumption.

\footnotetext{
${ }^{1}$ Professor Sênior da Escola Superior de Agricultura "Luiz de Queiroz" da USP e docente aposentado do Instituto de Economia da UNICAMP. Endereço para correspondência: Caixa Postal no 9 (ESALQ). CEP. 13418-900 - Piracicaba, São Paulo. E-mail: hoffmannr@usp.br. ID ORCID: 0000-0002-2077-8202

2 Doutor em Economia Aplicada pela Escola Superior de Agricultura “Luiz de Queiroz" da USP. Endereço para correspondência: Rua Manuel Lopes Velludo no 100, Radianza, apto. 33. CEP. 14027-035 - Ribeirão Preto, São Paulo. E-mail: jesus2.jgj@gmail.com. ID ORCID: 0000-0002-8287-6326
} 
Submetido em: 30/04/2021

Aceito em: 22/07/2021

\section{INTRODUÇÃO}

No momento em que este texto estava sendo redigido já se aproximava de 400 mil o número de brasileiros vítimas fatais do Covid-19. Além das perdas incomensuráveis de vidas, a pandemia também afetou fortemente a economia brasileira, agravando sobremaneira a crise existente desde 2014. De acordo com dados do IBGE[1], no quarto trimestre de 2020, o número de desocupados no país era da ordem de 13,9 milhões de pessoas, o que representa cerca de $14 \%$ de sua população economicamente ativa. Em meio a esse cenário desalentador de crises sanitária e econômica, de muita incerteza, com alta taxa de desemprego e pressão inflacionária, comer todos os dias passou a ser um desafio ainda maior para milhões de brasileiros.

Ainda maior porque, primeiro, o problema da fome no Brasil nunca foi completamente resolvido e, segundo, embora tenha se agravado no contexto da pandemia, os retrocessos em termos de distribuição de renda e pobreza já vinham ocorrendo desde 2015. Atualmente a atenção está focada na crise associada à pandemia do Covid 19, mas deve ficar claro que a situação socioeconômica do país já era muito frágil antes dessa nova crise, como mostra Hoffmann[2].

No cenário global, o Brasil ocupa papel relevante na economia, na política, na ciência, na cultura, no esporte e em outros tantos e variados campos de manifestação da atividade humana. Não obstante, nesse mesmo Brasil, enormes contingentes populacionais encontram-se na miséria e passam fome; a subnutrição e a insegurança alimentar ainda fazem parte do dia a dia de muitas pessoas. A persistência dessas privações às liberdades básicas individuais se deve menos à escassez absoluta ou relativa de recursos e muito mais ao elevado grau de desigualdade da sua distribuição. $\mathrm{O}$ padrão distributivo brasileiro é ímpar no rol das sociedades com níveis semelhantes de desenvolvimento. $\mathrm{O}$ Brasil se encontra entre os países com os mais elevados níveis de desigualdade de renda do mundo.
Não é novidade que nas sociedades mercantis o acesso a bens e serviços, isto é, o acesso a quase tudo considerado fonte de bem-estar, está intimamente associado ao poder aquisitivo do indivíduo ou, em última instância, ao poder aquisitivo do grupo familiar a que ele pertence. Em se tratando do Brasil, o estado garante acesso universal a serviços básicos como saúde e educação, mas o acesso à alimentação depende, em grande medida, da capacidade de os indivíduos pagarem por ela. Assim, na maioria dos casos, o dinheiro é o que permite ao indivíduo ter acesso a alimentos e poder saciar a mais básica das necessidades humanas. Sen ${ }^{[3]}$ mostra que a fome decorre, em geral, de as pessoas não terem acesso a uma quantidade suficiente de alimento, e não de não haver oferta suficiente de alimentos no mercado. Reiterando, mesmo o Brasil sendo um dos maiores produtores de alimento do mundo, milhões de pessoas, por insuficiência de renda, ainda convivem diariamente com a insegurança alimentar.

É bem verdade que no último meio século o debate sobre o consumo alimentar no Brasil passou por mudanças significativas, e hoje recai muito mais sobre a super ou má nutrição do que propriamente sobre a acessibilidade, a fome e a subnutrição. Mas o Brasil historicamente nunca deixou de ter problemas importantes de segurança alimentar, e em contexto de crise econômica, como esta existente desde 2014, agravada pela pandemia do Covid 19, a pressão sobre os mais pobres para colocar comida na mesa aumenta vertiginosamente.

Neste artigo não trataremos da questão da fome especificamente, mas achamos pertinente chamar a atenção para a questão. O que iremos discutir está mais associado à escolha alimentar. Sendo a renda o principal meio de acesso aos alimentos consumidos dentro dos domicílios, analisaremos como, no Brasil, alterações na renda familiar per capita impactam o consumo domiciliar de alimentos específicos. São apresentadas estimativas das elasticidades-renda do consumo (em quilogramas per capita) de grande número de alimentos (diversos tipos de frutas, hortaliças, leite, carnes etc.), utilizando os dados da Pesquisa de Orçamentos Familiares (POF) 2017-2018 sobre a quantidade adquirida pelas famílias. 
As familias da amostra da POF 2017-2018 são classificadas em 10 estratos de renda per capita, calcula-se o consumo médio de cada alimento nos 10 estratos (em quilogramas per capita por ano) e estimase a respectiva elasticidade-renda ajustando uma poligonal para a variação do logaritmo do consumo per capita em função do logaritmo da renda familiar per capita (RFPC). A mesma metodologia foi usada para estimar elasticidades-renda das despesas e do consumo físico de alimentos com dados da POF de 2002-2003[4] e da POF de 2008-2009[5] e também foi publicado trabalho analisando os dados sobre despesas coletados na POF 2017-2018[6]. A evolução, entre a POF de 2008-2009 e a POF de 2017-2018, de várias categorias de despesa, incluindo as despesas com alimentos, é analisada em Hoffmann e Vaz ${ }^{[7]}$.

Os dados da POF de 2017-2018 oferecem a possibilidade de investigar as modificações mais recentes no padrão de consumo alimentar dos brasileiros, atualizando os cálculos anteriores ${ }^{[4,5]}$, baseados nos dados das POF de 2002-2003 e de 2008-2009. Como a metodologia foi mantida inalterada e não houve mudanças significativas na forma de investigação adotada pela POF, este estudo e os já citados ${ }^{[4,5,6]}$ permitem acompanhar o comportamento da demanda dos consumidores por alimentos e as mudanças nos padrões alimentares na população nas últimas décadas, podendo auxiliar na formulação de políticas públicas nas áreas de alimentação e nutrição, bem como na elaboração de estratégias de mercado por parte da indústria alimentícia. Ao final é acrescentada uma discussão sobre a importância de se considerar as diferenças entre padrões alimentares nas áreas urbanas e rurais e os contrastes de hábitos alimentares entre as grandes regiões do país. Discute-se também como as variações de consumo inter-regionais associadas a diferenças inter-regionais de renda per capita impactam na estimativa da elasticidade-renda média para o país como um todo.

Este artigo está dividido em cinco seções, sendo esta introdução a primeira delas. A seção 2 consiste em uma breve revisão das mudanças observadas no padrão alimentar dos brasileiros nas últimas décadas. A seção 3 descreve a base de dados e a metodologia adotada para o ajuste da função poligonal. $\mathrm{Na}$ quarta seção são apresentados e discutidos os resultados. Na última seção estão as considerações finais.

\section{REVISÃO DA LITERATURA}

Os estudos voltados ao consumo das famílias são de grande importância. Trata-se de um dos principais componentes do Produto Interno Bruto (PIB). Sob a ótica da demanda, o consumo das famílias representa mais de $60 \%$ do PIB brasileiro.

Em se tratando dos gastos com alimentação, estes vêm perdendo importância no orçamento das famílias brasileiras nas últimas décadas, conforme mostram Vaz e Hoffmann ${ }^{[6]}$ com base em dados divulgados pelo IBGE[ ${ }^{[8]}$. De acordo com esses dados, a participação dos gastos com alimentação na despesa média mensal familiar, que era de 33,9\% em 1974-1975, caiu para 20,8\% em 2002-2003, para 19,8\% em 20082009 e para 17,5\% em 2017-2018. Os autores explicam que o crescimento da renda per capita e a redução da desigualdade em sua distribuição, ocorridos entre 2001 e 2014, ajudam a compreender essa alteração no padrão de consumo das famílias e ilustram o comportamento descrito pela Lei de Engel, que postula que a participação dos gastos com alimentação no orçamento das famílias tende a se reduzir à medida que sua renda aumenta.

Ainda de acordo com Vaz e Hoffmann[ [], além de perderem participação no orçamento familiar, as despesas com alimentação têm sofrido alterações em virtude de mudanças demográficas, educacionais e comportamentais, que afetam as decisões e preferências das familias sobre o que consumir e onde consumir. Os autores observaram, comparando dados referentes às três últimas edições da POF, uma tendência de redução do consumo de gêneros tradicionais, como arroz, feijão, batata, pão e açúcar, e aumento da aquisição de produtos industrializados, prontos para consumo ou de fácil preparo, e na expansão dos gastos com alimentação fora de casa. Dentre os fatores que ajudam a explicar essas e outras alterações nos padrões de consumo, os autores citam o aumento da escolaridade média da população, a queda da fecundidade, o aumento da longevidade, os processos de industrialização e urbanização e o ingresso crescente da mulher no mercado de trabalho (p. 284), sendo o aumento da parcela dos gastos familiares com alimentação fora do domicílio uma das mudanças mais evidentes nos hábitos alimentares da população ( $p$. 286). 
Em relação a este último ponto, Leal[ ${ }^{[9]}$ chama a atenção para a profusão e variedade de estabelecimentos comerciais destinados à preparação de refeições, que vão desde os tradicionais restaurantes à la carte, até os do tipo self service e "prato feito", passando pelas redes de lanchonetes fast food, bares, padarias, e incluindo os vendedores ambulantes. Sobre a questão do aumento do consumo de produtos industrializados, como consta em Vaz e Hoffmann[[], a depender da extensão de seu processamento industrial, estes podem ser classificados em in natura ou minimamente processados, processados e ultraprocessados.

Em estudo conduzido por Louzada et al. [10], com base nos dados de POF de 2008-2009, estimou-se que, em nível nacional, $21,5 \%$ do consumo médio diário de energia per capita provinham de alimentos ultraprocessados. Também com base nos dados da POF, Martins et al. ${ }^{[1]}$ mostram que a participação dos produtos ultraprocessados no consumo médio diário de calorias dos moradores dos domicílios metropolitanos brasileiros passou de 18,7\% em 19871988 para 29,6\% em 2008-2009. No grupo de alimentos ultraprocessados estão incluídos biscoitos doces e salgados, salgadinhos tipo chips, guloseimas em geral, lanches do tipo fast food, macarrão instantâneo, vários tipos de pratos prontos ou semiprontos e refrigerantes, conforme descrito por Louzada et al.[10]. Os autores explicam que esses alimentos apresentam, em média, características nutricionais desfavoráveis quando comparados aos alimentos in natura ou minimamente processados, como maior densidade energética, maior teor de gorduras, de sódio e de açúcar livre e menor teor de fibras e de proteínas, e seu consumo tem sido associado à maior prevalência de doenças cardiovasculares, diabetes e alguns tipos de câncer.

Conforme já mencionado, no último meio século, o debate sobre o consumo alimentar no país sofreu diversas mudanças, passando a recair menos sobre temas como fome e subnutrição e mais sobre questões associadas à escolha alimentar. Segundo Bertasso $^{[12]}$, essa mudança de perspectiva, em grande parte, é decorrência da menor incidência de casos de subnutrição observada sobretudo a partir de meados da década de 90 e da concomitante elevação dos índices de doenças advindas da má alimentação dos brasileiros. Assim, à medida que o país amenizava um grave problema social, deparava-se com uma nova problemática, com sérias repercussões na área de saúde pública: a má nutrição e a obesidade.

De acordo com Bleil[13], a má alimentação, cujas características gerais são ser irregular, ligeira, e de baixa adequação nutricional, decorre não só das exigências da vida moderna, nos grandes centros urbanos, dada a escassez de tempo das pessoas, mas também da exploração do alimento como uma mercadoria qualquer, com grande apelo na mídia.

Mais recentemente, devido ao grande aumento da incidência de casos de sobrepeso e obesidade associados à má alimentação, a qualidade dos alimentos passou a ser uma questão de grande relevância, levando à expansão da demanda por alimentos com atributos especiais, como os light, os diet e os orgânicos, conforme discutido em Oliveira e Hoffmann ${ }^{[14]}$.

Os autores explicam que o aumento da conscientização de uma parcela de consumidores, preocupados com as práticas alimentares não saudáveis, deu espaço ao mercado de produtos orgânicos, caracterizado por consumidores que apresentam interesse em saber de onde vem o alimento e como ele foi processado. A preocupação com o meio ambiente e o consumo sustentável também têm estimulado novos hábitos, dando espaço para esse tipo de produto.

Neste mesmo caminho, a busca pelo equilíbrio entre saúde e estética levou parte dos consumidores a optarem pelos produtos industrializados com menor densidade calórica, como os light e diet. Em estudo realizado em meados dos anos 2000, Lucchese et al..$^{[15]}$ mostraram que, embora o maior volume de compra de produtos light e diet ainda fosse realizado pelas classes mais ricas, o volume desses produtos adquirido pela classes de menor poder aquisitivo já despertava, nas indústrias do setor, $\mathrm{o}$ interesse $\mathrm{em}$ conhecer $\mathrm{e}$ conquistar esses novos consumidores.

Os resultados apresentados por Oliveira e Hoffmann [14], com base nos microdados da POF de 2008-2009, mostram que a probabilidade de uma família consumir esses alimentos especiais (orgânicos, light e diet) cresce com a renda e com a escolaridade e que a residência urbana contribui para o consumo de alimentos light/diet, mas não para o consumo de produtos orgânicos. Mostram, ainda, que a elasticidaderenda dos alimentos orgânicos e dos alimentos light/ diet é substancialmente maior que a dos alimentos 
correspondentes sem esses atributos especiais. Os resultados acerca das elasticidades-renda foram corroborados por Vaz e Hoffmann[6], com base nos microdados da POF de 2017/2018, mostrando que os produtos orgânicos e light/diet são mais demandados pelos relativamente ricos e possuem potencial de crescimento do consumo no mercado interno.

Hoffmann ${ }^{[16]}$, com base nos microdados da POF de 1995-1996, apresenta de forma detalhada a composição dos gastos com alimentação nas regiões metropolitanas brasileiras, além de incluir uma discussão sobre pobreza e distribuição do rendimento familiar. O autor emprega um modelo econométrico para ajustar uma poligonal e calcular as elasticidadesrenda de onze grandes grupos de consumo (alimentação, habitação, vestuário, transporte, higiene e cuidados pessoais, assistência à saúde, educação, recreação e cultura, fumo e despesas diversas) e na sequência estimar a elasticidade-renda da despesa e do consumo físico de uma cesta composta por mais de 40 subitens do grupo alimentação, comparando os resultados encontrados.

Os resultados mostraram que, por um lado, quando o produto não é homogêneo e os relativamente ricos compram, em maior proporção, um produto de melhor qualidade e mais caro, a elasticidade-renda da despesa com o produto tenderá a ser maior do que a elasticidade-renda do consumo físico. Por outro lado, muitas vezes os mais pobres, por limitações de transporte ou por serem dependentes do crédito concedido por certos comerciantes, pagam um preço mais elevado, fazendo com que a elasticidade-renda da despesa se mostre menor do que a elasticidade-renda do consumo físico.

Também tomando por base os dados da POF de 1995-1996, Meneses et al.[17] utilizam uma expansão quadrática do modelo Almost Ideal Demand System (AIDS) para o cálculo da elasticidade-despesa de 39 produtos do grupo alimentação. A elasticidade-renda da despesa foi comparada entre faixas de renda e grandes regiões. Os resultados encontrados apontaram uma grande variação no padrão de consumo não só em função da renda, mas também entre regiões. Em linha parecida, usando os dados da POF de 2002-2003, Schlindwein e Kassouf ${ }^{[18]}$ utilizaram modelos de escolha binária para analisar o padrão de consumo de alimentos tempo-intensivos (feijão, arroz, carnes e farinha de trigo) e de alimentos poupadores de tempo (alimentação fora de casa, alimentos prontos, iogurte e pão), por região do Brasil.

Os resultados apresentados por Schlindwein e Kassouf ${ }^{18]}$ mostraram que uma elevação na renda teve um efeito positivo no dispêndio em todas as regiões e com todos os produtos analisados, e que em todas as regiões brasileiras, o maior efeito foi observado sobre o dispêndio com alimentação fora de casa e alimentos prontos e o menor sobre o dispêndio com feijão e arroz. O estudo também constatou que, de um modo geral, em todas as regiões do país, a urbanização, o aumento da participação da mulher no mercado de trabalho e a escolaridade da mulher afeta positivamente o consumo de alimentos poupadores de tempo e negativamente $o$ consumo de alimentos tempo-intensivos.

As autoras não deixaram de chamar a atenção para o fato de que essa mudança nos hábitos alimentares, com a redução no consumo de alimentos considerados muito saudáveis, como o feijão e o arroz, e um aumento no consumo de uma alimentação mais rápida como, por exemplo, os alimentos prontos, pode, no futuro, levar a problemas de saúde para a população, devido, principalmente, à grande incidência de conservantes nesses produtos, além de muitas vezes não estarem corretamente balanceados ou não oferecerem todos os nutrientes necessários para uma alimentação saudável.

A edição da POF de 2002-2003 foi a primeira de abrangência nacional, e foi utilizada por Hoffmann ${ }^{[4]}$ para replicar as análises contidas em trabalho anterior ${ }^{[16]}$ acerca das estimativas das elasticidades-renda das despesas e do consumo físico de alimentos. Mas, no artigo de 2007[4], o autor acrescenta uma discussão sobre a importância de se considerar as diferenças entre padrões alimentares nas áreas urbanas e rurais e os contrastes de hábitos alimentares entre as regiões deste imenso país. Como exemplo dessas diferenças, o autor examina o consumo físico de farinha de mandioca em várias situações geográficas. Verificou que o consumo médio de farinha de mandioca nas áreas rurais do Brasil é mais de quatro vezes maior do que nas áreas urbanas, e que as diferenças entre regiões são mais drásticas: enquanto no Estado de São Paulo o consumo anual per capita não atingia $1 \mathrm{~kg}$, no Nordeste superava os $15 \mathrm{~kg}$, e na região Norte era próximo de $34 \mathrm{~kg}$. Constatou que também havia diferenças substanciais na estimativa da elasticidade-renda. Seu valor absoluto era menor na área rural $(-0,283)$ do que na área urbana $(-0,562)$ e bem 
menor no Nordeste $(-0,146)$ do que no Estado de São Paulo $(-0,523)$. E quando separou o Nordeste rural, observou que a elasticidade média estimada se tornava positiva $(0,222)$.

Com a publicação dos dados da POF de 20082009, foi possível atualizar as estimativas das elasticidades-renda das despesas e do consumo físico de alimentos no Brasil (Hoffmann ${ }^{[5]}$ ). Com o presente estudo, concentrado apenas nas estimativas das elasticidades-renda do consumo físico de alimentos no Brasil, uma vez que a análise das estimativas das elasticidades-renda das despesas com alimentos já foi elaborada por Vaz e Hoffmann ${ }^{[3]}$, estarão atualizadas as séries, com base nos dados da POF, das estimativas das elasticidades-renda das despesas e do consumo físico de uma ampla cesta de alimentos consumidos pelos brasileiros.

Como a metodologia foi mantida inalterada e não houve mudanças significativas na forma de investigação adotada pela POF, estes estudos permitem acompanhar o comportamento da demanda dos consumidores por alimentos e as mudanças nos padrões alimentares na população nas últimas décadas, podendo auxiliar na formulação de políticas públicas nas áreas de alimentação e nutrição, bem como na elaboração de estratégias de mercado por parte da indústria alimentícia.

\section{MATERIAL E MÉTODOS}

\subsection{Base de dados}

O acompanhamento das modificações temporais e regionais no padrão de consumo é feito a partir de pesquisas domiciliares. A primeira pesquisa com abrangência nacional realizada com esta finalidade, no Brasil, foi o Estudo Nacional da Despesa Familiar (Endef), implementada pelo IBGE no período de 19741975. Na década de 1980, o desenho amostral do Endef foi substituído pela Pesquisa de Orçamentos Familiares (POF), também do IBGE. A POF tem sido realizada com uma periodicidade em torno de sete anos, e está disponível para os anos de 1987-1988, 1995-1996, 2002-2003, 2008-2009 e 20017-2018. Aquelas de 19871988 e 1995-1996 pesquisaram as nove principais regiões metropolitanas (São Paulo, Rio de Janeiro, Belo Horizonte, Salvador, Recife, Fortaleza, Belém, Curitiba e Porto Alegre), além do Distrito Federal e da cidade de
Goiânia. A de 2002-2003 e as duas seguintes tiveram abrangência nacional.

No presente estudo foram utilizados os dados da Pesquisa de Orçamentos Familiares (POF) 20172018 sobre o rendimento familiar e a quantidade de alimentos adquirida pelas famílias. A amostra inclui 58.039 famílias ou "unidades de consumo" e 178.431 pessoas, que, ponderadas pelos fatores de expansão fornecidos com a pesquisa, correspondem a uma população de 69.017.704 famílias e 207.103.790 indivíduos.

\subsection{Metodologia}

Apresentações da metodologia de estimação da elasticidade-renda com base no ajuste de uma poligonal com três segmentos podem ser encontradas nos trabalhos citados[4,5,6,16]. Aqui vamos mostrar o procedimento passo-a-passo, utilizando como exemplo o consumo de mamão.

A partir dos microdados da POF 2017-2018 podemos construir a Tabela 1, na qual as familias (as Unidades de Consumo da POF) e as pessoas são distribuídas em dez classes de renda per capita. A segunda classe, por exemplo, inclui as famílias cuja renda familiar per capita vai de mais de $\mathrm{R} \$ 400$ a $\mathrm{R} \$ 700$. Os limites entre as classes foram escolhidos evitando que qualquer das classes ficasse com uma proporção muito alta das pessoas ou da renda. Nas duas primeiras classes estão $31,5 \%$ das pessoas, que ficam com $7,2 \%$ da renda. No outro extremo, os 6,0\% mais ricos ficam com 33,4\% da renda total declarada. O índice de Gini dessa distribuição é igual a 0,535[7].

Pode-se verificar que o número médio de pessoas por família é igual a 3,00 e que ele cai continuamente de 4,27 na primeira classe para 2,05 na última classe[]. Vamos indicar por $X_{i}$, com $i=$ $1,2, \ldots, 10$, o logaritmo neperiano da renda per capita média em cada classe. Analogamente, indicamos por $Y_{i}$ o logaritmo neperiano do consumo médio anual per capita do alimento analisado; no caso, $Y_{i}$, em cada classe, é o logaritmo neperiano do valor apresentado na última coluna da Tabela 1. Os dez pares de valores $\left(X_{i}, Y_{i}\right)$ correspondem aos dez pontos azuis na Figura 1. 
Tabela 1. Pessoas, famílias, renda e consumo de mamão por classe da renda familiar per capita, Brasil, 2017-2018

\begin{tabular}{|c|c|c|c|c|c|c|c|}
\hline \multirow{2}{*}{$\begin{array}{l}\text { Classes da renda familiar per capita }{ }^{(1)} \\
\qquad(\mathrm{R} \$)\end{array}$} & \multicolumn{2}{|c|}{ Pessoas } & \multicolumn{2}{|c|}{ Famílias } & \multirow{2}{*}{$\begin{array}{c}\text { Renda } \\
\text { familiar per } \\
\text { capita }^{(1)}(\mathrm{R} \$)\end{array}$} & \multirow{2}{*}{$\begin{array}{c}\% \text { da } \\
\text { renda } \\
\text { total na } \\
\text { classe }\end{array}$} & \multirow{2}{*}{$\begin{array}{l}\text { Consumo anual } \\
\text { de mamão em } \\
\text { kg per capita }\end{array}$} \\
\hline & $\begin{array}{l}\text { Número } \\
\text { (mil) }\end{array}$ & $(\%)$ & $\begin{array}{l}\text { Número } \\
\text { (mil) }\end{array}$ & $(\%)$ & & & \\
\hline De 0 a 400 & 29.796 & 14,39 & 6.979 & 10,11 & 257,54 & 2,05 & 0,427 \\
\hline Mais de 400 a 700 & 35.484 & 17,13 & 9.534 & 13,81 & 546,79 & 5,18 & 0,525 \\
\hline Mais de 700 a 1.000 & 31.632 & 15,27 & 9.424 & 13,66 & 842,56 & 7,12 & 0,695 \\
\hline Mais de 1.000 a 1.300 & 25.402 & 12,27 & 8.763 & 12,70 & $1.145,71$ & 7,77 & 1,122 \\
\hline Mais de 1.300 a 1.600 & 18.818 & 9,09 & 7.073 & 10,25 & $1.442,44$ & 7,25 & 1,407 \\
\hline Mais de 1.600 a 2.000 & 16.971 & 8,19 & 6.563 & 9,51 & $1.784,78$ & 8,09 & 2,056 \\
\hline Mais de 2.000 a 3.000 & 21.353 & 10,31 & 8.717 & 12,63 & $2.418,12$ & 13,79 & 2,994 \\
\hline Mais de 3.000 a 5.000 & 15.268 & 7,37 & 6.307 & 9,14 & $3.777,09$ & 15,40 & 4,368 \\
\hline Mais de 5.000 a 10.000 & 8.694 & 4,20 & 3.861 & 5,59 & $6.872,73$ & 15,95 & 7,309 \\
\hline Mais de 10.000 & 3.686 & 1,78 & 1.795 & 2,60 & $17.692,01$ & 17,41 & 9,317 \\
\hline Total & 207.104 & 100,00 & 69.018 & 100,00 & $1.808,46$ & 100,00 & 1,795 \\
\hline
\end{tabular}

Fonte: Elaborada a partir dos microdados da POF 2017-2018

(1) Em reais de 15 de janeiro de 2018.

Para ajustar uma poligonal com três segmentos aos dez pontos, é necessário agrupar as dez classes em três grandes estratos. Há 36 diferentes maneiras de fazer isso. Adiante veremos como é escolhida a melhor alternativa. No caso do consumo de mamão, como mostra a Figura 1, escolhemos o esquema 2-5-3, ou seja, o primeiro grande estrato (correspondendo ao primeiro segmento da poligonal) agrupa as duas primeiras classes de renda per capita, o segundo grande estrato (segundo segmento da poligonal) inclui as cinco classes seguintes e as três últimas classes formam o terceiro estrato (terceiro segmento da poligonal). As abscissas dos dois vértices da poligonal são, neste caso, os logaritmos dos limites superiores da segunda $\left(\theta_{1}=\right.$ $\ln (700)=6,551)$ e da sétima classe $\left(\theta_{2}=\ln (3.000)=\right.$ $8,006)$.

Figura 1. Variação do consumo anual per capita de mamão em função da renda familiar per capita no Brasil, 2017-2018

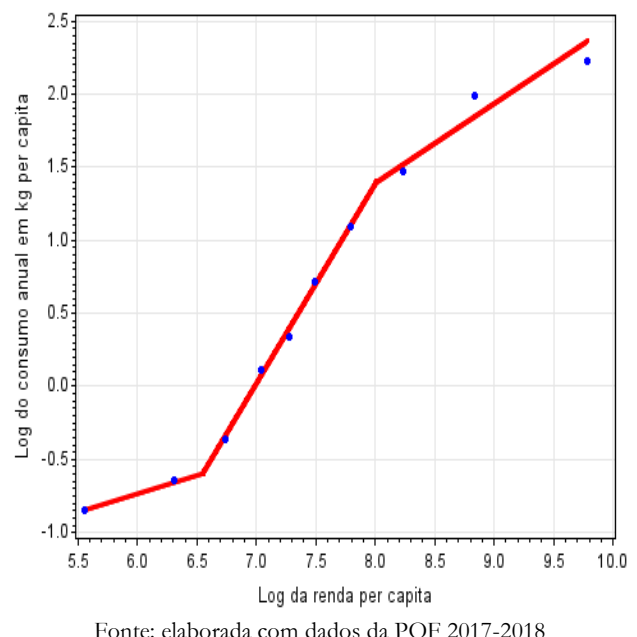


Seja $Z_{1 i}$ uma variável binária que é igual a zero para $X_{i} \leq \theta_{1}$ e é igual a 1 para $X_{i}>\theta_{1}$. Analogamente, seja $Z_{2 i}$ uma variável binária que é igual a zero para $X_{i} \leq$ $\theta_{2}$ e é igual a 1 para $X_{i}>\theta_{2}$. Então o modelo da equação de regressão correspondente a uma linha poligonal com três segmentos é

$$
Y_{i}=\alpha+\beta X_{i}+\delta_{1} Z_{1 i}\left(X_{i}-\theta_{1}\right)+\delta_{2} Z_{2 i}\left(X_{i}-\theta_{2}\right)+u_{i}
$$

onde $u_{i}$ representa um erro aleatório com as propriedades usuais. No primeiro grande estrato, $\operatorname{com} Z_{1 i}=Z_{2 i}=0$, a equação se reduz a $Y_{i}=\alpha+\beta X_{i}+$ $u_{i}$, mostrando que a elasticidade-renda nesse estrato é $\beta$ (o coeficiente que mostra como o logaritmo do consumo per capita varia em função do logaritmo da renda per capita). No segundo grande estrato, com $Z_{1 i}=1$ e $Z_{2 i}=0$, podemos verificar que a equação simplifica para $Y_{i}=\alpha-\delta_{1} \theta_{1}+\left(\beta+\delta_{1}\right) X_{i}+u_{i}$, mostrando que nesse intervalo a elasticidade-renda é igual a $\beta+\delta_{1}$. Finalmente, no terceiro grande estrato, com $Z_{1 i}=Z_{2 i}=1$, a equação pode ser escrita como $Y_{i}=\alpha-\delta_{1} \theta_{1}-\delta_{2} \theta_{2}+\left(\beta+\delta_{1}+\delta_{2}\right) X_{i}+u_{i}, \quad$ com elasticidade- renda dada por $\beta+\delta_{1}+\delta_{2}$. Para os dados de consumo per capita de mamão apresentados na Tabela 1 , a equação estimada é

$$
\hat{Y}_{i}=-2,2507+0,2527 X_{i}+1,1166 Z_{1 i}\left(X_{i}-\theta_{1}\right)-0,8261 Z_{2 i}\left(X_{i}-\theta_{2}\right)
$$

com coeficiente de determinação múltipla $\left(R^{2}\right)$ igual a 0,997 . As elasticidades-renda nos três grandes estratos são $0,253,0,2527+1,1166=1,369$ e $0,2527+$ $1,1166-0,8261=0,543$, conforme consta na Tabela 2 , na seção de resultados. A elasticidade-renda média é a média ponderada das elasticidades nos três estratos, usando como fator de ponderação a participação dos estratos no consumo total. No caso do mamão, o primeiro estrato participa com $8,43 \%$ do consumo total, o segundo estrato com $47,29 \%$ e o terceiro com 44,28\%. Então a elasticidade média é $0,0843 \cdot 0,253+0,4729 \cdot 1,369+0,4428 \cdot 0,543=0,909$, que também está na Tabela 2 . Esse resultado significa que um aumento de $10 \%$ na renda per capita das familias brasileiras leva a um aumento de 9,09\% no consumo doméstico de mamão.

Para escolher a maneira de agrupar as dez classes de renda per capita em três grandes estratos, foi elaborado um programa de computador que estima as equações para as 36 combinações possíveis e as ordena conforme valores crescentes do coeficiente de determinação $\left(R^{2}\right)$. Geralmente foi escolhida a equação com o maior $R^{2}$. Em alguns casos, para evitar estimativas discrepantes, optamos por modelos com $R^{2}$ um pouco inferior ao máximo observado. Há, entretanto, casos em que o ajuste é ruim e são obtidas estimativas de elasticidades-renda estranhas em algum dos estratos, como é o caso do consumo de sal refinado. Note-se, entretanto, que mesmo nesse caso a elasticidade-renda média é razoável.

Cabe ressaltar que seria totalmente inapropriado estimar a elasticidade-renda por meio de uma regressão do logaritmo do consumo per capita contra o logaritmo da renda per capita, usando os dados de cada família da amostra da POF. Além do problema de termos de descartar todas as famílias com consumo igual a zero (já que não se define logaritmo de zero), o fato de a variável explanatória (a renda per capita) estar sujeita a grandes erros de medida causa forte subestimação do coeficiente de regressão. $\mathrm{O}$ uso das médias nas dez classes de renda per capita minimiza essa subestimação do coeficiente de regressão associada aos erros de medida na variável explanatória.

O procedimento que utilizamos não leva a uma estimativa coeteris paribus (mantendo constantes todos os demais fatores) da variação no consumo per capita do produto em função do crescimento da renda per capita. Juntamente com o efeito da variação da renda per capita, o método capta o efeito de todos os fatores que mudam junto com a renda per capita ao longo das dez classes de renda. É o caso típico da escolaridade. Na POF 2017-2018, a escolaridade média da pessoa de referência da família é igual a 9,0 anos para toda a população e cresce de 6,5 anos na primeira classe de renda para 15,6 anos na décima classe $^{3}$. A rigor, ao interpretar a estimativa da elasticidade-renda do consumo de mamão, seria necessário dizer que um aumento de $10 \%$ na renda per capita de todos os brasileiros, acompanhado pelas mudanças em escolaridade e outras características associadas a tal mudança de renda na população do 
País, levaria a um aumento de 9,09\% no consumo doméstico de mamão.

É importante lembrar que os dados da POF que analisamos se referem apenas ao consumo domiciliar. O consumo fora do domicílio tende a se tornar cada vez mais importante. Conforme dados da POF 2002-2003, a alimentação fora do domicílio representava $24,0 \%$ do total de despesas com alimentação. Essa porcentagem subiu para $31,1 \%$ na POF 2008-2009 e para 32,8\% na POF 2017-2018.

\section{RESULTADOS}

\subsection{Elasticidades-renda do consumo físico de alimentos}

Os resultados obtidos com o ajustamento do modelo poligonal aos dados sobre consumo de alimentos no domicílio são apresentados na Tabela 2.

A lista é encabeçada por dois alimentos básicos: "Arroz" e "Feijão". Para ambos, a elasticidade média é próxima de zero. Um crescimento proporcional da renda de todos os brasileiros não deverá causar aumento na demanda por esses produtos para consumo nos domicílios. Verifica-se que a elasticidade-renda é ligeiramente positiva no estrato mais pobre. A "Farinha de mandioca" se destaca pelo fato de a estimativa dessa elasticidade ser negativa nos três estratos correspondentes aos segmentos da poligonal ajustada. Outros casos de elasticidades-renda médias negativas se explicam pela tendência de os relativamente ricos substituírem o produto por um semelhante e de melhor qualidade, sendo exemplo o "Macarrão sem ovos", que é substituído por "Macarrão com ovos".

Comparando os resultados na última coluna da Tabela 2 com os correspondentes na última coluna da Tabela 4 do estudo realizado por Vaz e Hoffmann ${ }^{[6]}$, verifica-se que, em geral, a elasticidaderenda da despesa é maior do que a elasticidade-renda do consumo (em $\mathrm{kg}$ ), pois o produto adquirido pelas familias relativamente ricas tende a ser de melhor qualidade (e mais caro) do que o adquirido pelas familias relativamente pobres.
Isso fica mais evidente quando se considera um agregado de produtos relativamente heterogêneo. Assim, a elasticidade-renda do consumo de "Queijos" é 0,834, ao passo que a elasticidade-renda das despesas correspondentes é 0,897 e para "Macarrão" essas elasticidades são 0,083 e 0,177 , respectivamente. Para produtos relativamente homogêneos, embora o padrão geral se mantenha, com a elasticidade das despesas maior do que a do consumo físico, elas são numericamente muito semelhantes. É o que ocorre, por exemplo, para "Arroz", "Feijão", "Farinha de trigo", "Açúcar refinado", "Ovo de galinha", "Bananas", "Laranja", "Massa de tomate" e "Sal refinado". Mas, há também produtos para os quais a elasticidade-renda da despesa é menor do que a elasticidade-renda da quantidade consumida. Isso pode ser explicado pela possibilidade de os relativamente ricos obterem preços mais baixos por comprarem em maior escala e/ou em locais mais distantes de suas residências. São exemplos "Óleo de soja" e "Refrigerantes".

Cabe ressaltar que o cálculo da elasticidade do consumo perde sentido no caso de agregados muito heterogêneos, pois implica em somar quilogramas de produtos muito diferentes ${ }^{[16]}$. Ademais, de maneira geral, é recomendável não confiar demasiadamente nas elasticidades estimadas para cada estrato. Note-se que em muitos casos um estrato é formado por apenas uma classe de recebimento, dando origem a uma estimativa de elasticidade imprecisa e que se refere a uma parcela restrita da população. A elasticidade média depende da posição de toda a poligonal ajustada ao conjunto de dez pontos. Nesse sentido, a elasticidade média é bem mais confiável do que as estimativas das elasticidades em cada estrato.

Note-se que os coeficientes de determinação $\left(R^{2}\right)$ das equações ajustadas são geralmente superiores a $95 \%$. Porém, cabe destacar que um valor baixo do coeficiente de determinação não significa, necessariamente, que a elasticidade média não seja confiável. Por ser relativamente essencial e ter participação minúscula no orçamento doméstico, o "Sal refinado" é um exemplo clássico de produto cujo consumo quase não depende da renda. Assim, a regressão ajustada apresenta coeficiente de determinação relativamente baixo $(0,715)$ e indica, corretamente, uma elasticidade-renda próxima de zero. 
De um modo geral, as elasticidades médias estimadas se mostram coerentes com o esperado. $\mathrm{Na}$ Tabela 2 observa-se que a elasticidade-renda é mais alta para os alimentos mais "nobres" ou relativamente caros, que, por isso mesmo, só são consumidos em maior quantidade pelos relativamente ricos. Compare-se, por exemplo, a elasticidade-renda do consumo de "Carne bovina de primeira" $(0,613)$ com a elasticidade-renda do consumo de "Carne bovina de segunda" $(0,204)$ ou a elasticidade-renda do consumo de "Bananas" $(0,511)$ com a elasticidade-renda do consumo de frutas mais caras como "Ameixas" $(0,996)$, "Peras" $(1,001)$ ou "Pêssegos" (0,932) ou, ainda, compare-se a elasticidade-renda do consumo de "Leite de vaca" $(0,369)$ com a elasticidade-renda do consumo de "Queijo prato" $(0,897)$.

Um comportamento esperado para a elasticidade-renda do consumo de um alimento, sendo que o mesmo é valido para a elasticidade-renda das despesas, é um decréscimo do seu valor na passagem do primeiro para o segundo estrato e um novo decréscimo na passagem para o estrato de rendas mais elevadas, como ocorre no caso de "Batata-inglesa", "Tomate", "Peito de frango" e "Pão francês".

Outro comportamento esperado é um crescimento da elasticidade do primeiro para o segundo estrato e um decréscimo do segundo para o terceiro estrato. Esse seria o caso de produtos cujo consumo só cresce mais rapidamente depois de atingido um certo nível de renda. Esse comportamento é observado, no caso de "Frutas" de um modo geral, "Carne de boi de primeira", "Queijos", "Refrigerantes" e "Cervejas".

Também há casos em que o comportamento da elasticidade é inesperado, como para "Feijão", "Macarrão", "Óleo de Soja”. Era esperado o valor positivo no primeiro estrato, mas é estranho que a estimativa seja fortemente negativa em um estrato intermediário e volte a ser positiva para um estrato de rendas mais elevadas. Mas novamente, é recomendável não confiar demasiadamente nas elasticidades estimadas para cada estrato.

Conforme mencionado anteriormente, Hoffmann ${ }^{[4,5]}$ analisou os dados das edições da POF de 2002-2003 e de 2008-2009. Comparando os resultados sobre as quantidades consumidas de alimentos nos domićlios, apresentados nos dois artigos citados, com os resultados apresentados na Tabela 2, verifica-se uma redução substancial no consumo domiciliar médio per capita de alimentos tradicionais como arroz, feijão e macarrão, farinha de trigo, farinha de mandioca, batata inglesa, açúcar cristal, leite de vaca, óleo de soja e sal. O consumo domiciliar médio per capita de arroz caiu de $31,6 \mathrm{~kg}$ em 2002-2003 para 26,4 kg em 2008-2009 e para 19,7 $\mathrm{kg}$ em 2017-2018. No caso do feijão, o consumo domiciliar médio per capita que era de $12,4 \mathrm{~kg}$ em 2002-2003, caiu para 9,2 kg em 2008-2009 e para 6,2 $\mathrm{kg}$ em 2017-2018. No mesmo período (20022003/2017-2018), houve redução de $27,2 \%$ no consumo médio per capita de macarrão, de 56,1\% no consumo de farinha de trigo, de $70,0 \%$ no consumo de farinha de mandioca, de $23,8 \%$ no consumo de batata inglesa, de 50,3\% no consumo de açúcar cristal, de 43,9\% no consumo de leite de vaca, de $37,5 \%$ no consumo de óleo de soja e 50,8\% no consumo de sal.

Em se tratando proteína animal, o consumo médio per capita de "Carne bovina de primeira" caiu de 6,03 kg para 4,77 kg entre 2002-2003 e 2017-2018 e o de "Carne bovina de segunda" de 7,08 kg para $4,75 \mathrm{~kg}$ no mesmo período. Em termos percentuais, a redução foi de $20,8 \%$ no primeiro caso e de 32,8\% no segundo. A redução no consumo de carne de frango foi menos expressiva $(9,4 \%)$, passando de $13,34 \mathrm{~kg}$ para 12,01 $\mathrm{kg}$ entre as duas datas. Já o consumo médio per capita de "Ovo de galinha" aumentou $92,3 \%$ no mesmo espaço de tempo. No caso das frutas, verifica-se uma redução no consumo per capita daquelas consideradas mais populares, como "Bananas", "Laranja", "Tangerina" e "Mamão" e aumento no consumo daquelas consideradas mais nobres, como "Pera", "Ameixa", "Melão" e "Uva". 
Tabela 2. Consumo anual médio, em quilogramas, por família e per capita, e estimativa da elasticidade-renda de alimentos, no Brasil, com base em dados da POF 2017-2018

\begin{tabular}{|c|c|c|c|c|c|c|c|c|}
\hline \multirow{2}{*}{ Tipo de Alimento } & \multicolumn{2}{|c|}{ Consumo anual (kg) } & \multirow{2}{*}{$\begin{array}{l}\text { Esquema de } \\
\text { agrupamento }\end{array}$} & \multirow{2}{*}{$R^{2}$} & \multicolumn{3}{|c|}{ Elasticidade no Estrato } & \multirow{2}{*}{$\begin{array}{c}\text { Elasticidade } \\
\text { Média }\end{array}$} \\
\hline & por família & per capita & & & $\mathrm{I}$ & II & III & \\
\hline Arroz ${ }^{(1)}$ & 59,218 & 19,735 & $3-4-3$ & 0,916 & 0,041 & $-0,063$ & $-0,293$ & $-0,038$ \\
\hline Arroz polido & 54,685 & 18,224 & $3-4-3$ & 0,948 & 0,055 & $-0,088$ & $-0,346$ & $-0,046$ \\
\hline Arroz não espec. & 4,619 & 1,539 & $1-1-8$ & 0,636 & 0,601 & $-0,836$ & 0,201 & 0,080 \\
\hline Feijão & 18,750 & 6,248 & $7-2-1$ & 0,872 & 0,058 & $-0,501$ & 0,746 & 0,010 \\
\hline Feijão preto & 3,891 & 1,297 & $7-2-1$ & 0,957 & 0,336 & $-0,451$ & 0,297 & 0,224 \\
\hline Feijão rajado & 7,848 & 2,615 & $6-3-1$ & 0,794 & 0,117 & $-0,285$ & 0,373 & 0,035 \\
\hline Feijão mulatinho & 2,075 & 0,692 & $8-1-1$ & 0,813 & $-0,118$ & $-2,811$ & 2,752 & $-1,127$ \\
\hline Macarrão (1) & 9,357 & 3,118 & $7-2-1$ & 0,828 & 0,113 & $-0,296$ & 0,819 & 0,083 \\
\hline Macarrão s/ ovos & 2,327 & 0,775 & $6-3-1$ & 0,837 & 0,047 & $-0,499$ & 1,858 & $-0,009$ \\
\hline Macarrão c/ ovos & 2,429 & 0,809 & $1-5-4$ & 0,976 & 0,645 & 0,393 & $-0,080$ & 0,265 \\
\hline Far. de trigo & 6,689 & 2,229 & $2-4-4$ & 0,969 & 0,511 & 0,662 & $-0,252$ & 0,341 \\
\hline Far. Mandioca & 6,998 & 2,332 & $7-1-2$ & 0,963 & $-0,424$ & $-0,907$ & $-0,065$ & $-0,434$ \\
\hline Batata inglesa & 12,055 & 4,017 & $2-5-3$ & 0,994 & 0,675 & 0,482 & 0,039 & 0,418 \\
\hline Batata doce & 3,730 & 1,243 & $5-4-1$ & 0,986 & 0,779 & 0,466 & $-1,443$ & 0,569 \\
\hline Cenoura & 4,483 & 1,494 & $1-3-6$ & 0,995 & 0,065 & 0,785 & 0,312 & 0,461 \\
\hline Mandioca & 3,957 & 1,319 & $3-2-5$ & 0,952 & 0,378 & 0,875 & $-0,093$ & 0,304 \\
\hline Açúcar refinado & 11,114 & 3,704 & $4-2-4$ & 0,660 & 0,128 & 0,570 & $-0,156$ & 0,144 \\
\hline Açúcar cristal & 18,149 & 6,048 & $5-3-2$ & 0,976 & 0,192 & $-0,471$ & $-0,114$ & 0,009 \\
\hline Chuchu & 1,952 & 0,651 & $4-3-3$ & 0,992 & 0,830 & 0,700 & $-0,040$ & 0,563 \\
\hline Tomate & 12,631 & 4,209 & $1-8-1$ & 0,994 & 0,524 & 0,467 & $-0,194$ & 0,444 \\
\hline Abóbora & 3,067 & 1,022 & $2-2-6$ & 0,992 & 0,433 & 1,056 & 0,262 & 0,484 \\
\hline Cebola & 9,313 & 3,104 & $1-7-2$ & 0,999 & 0,364 & 0,442 & 0,117 & 0,399 \\
\hline Alho & 1,534 & 0,511 & $3-2-5$ & 0,995 & 0,414 & 0,909 & 0,151 & 0,404 \\
\hline Alface & 2,071 & 0,690 & $3-4-3$ & 0,998 & 0,896 & 0,644 & 0,187 & 0,581 \\
\hline Couve-flor & 0,333 & 0,111 & $2-6-2$ & 0,994 & 0,852 & 1,428 & $-0,153$ & 0,997 \\
\hline Couve & 0,893 & 0,298 & $1-6-3$ & 0,992 & 0,846 & 0,737 & 0,026 & 0,556 \\
\hline Brócolis & 0,407 & 0,135 & $2-5-3$ & 0,982 & 0,463 & 1,682 & 0,503 & 1,026 \\
\hline Frutas ${ }^{(1)}$ & 79,267 & 26,416 & $2-5-3$ & 0,998 & 0,585 & 0,801 & 0,295 & 0,621 \\
\hline Banana (1) & 21,241 & 7,079 & $2-4-4$ & 0,995 & 0,520 & 0,729 & 0,274 & 0,511 \\
\hline Laranja (1) & 12,856 & 4,284 & $2-5-3$ & 0,994 & 0,610 & 0,867 & 0,187 & 0,636 \\
\hline Maçã & 6,361 & 2,120 & $2-4-4$ & 0,994 & 0,521 & 0,903 & 0,286 & 0,576 \\
\hline Limão & 2,426 & 0,809 & $1-6-3$ & 0,985 & 0,598 & 1,068 & 0,305 & 0,789 \\
\hline Tangerina & 2,962 & 0,987 & $1-6-3$ & 0,997 & 0,557 & 1,139 & 0,216 & 0,803 \\
\hline Abacaxi & 4,178 & 1,392 & $6-2-2$ & 0,985 & 0,736 & 0,581 & 0,198 & 0,609 \\
\hline Abacate & 0,962 & 0,321 & $4-2-4$ & 0,987 & 0,764 & 1,544 & 0,611 & 0,826 \\
\hline Caqui & 0,485 & 0,161 & $1-2-7$ & 0,973 & 4,637 & 0,349 & 1,035 & 0,959 \\
\hline Mamão & 5,386 & 1,795 & $2-5-3$ & 0,997 & 0,253 & 1,369 & 0,543 & 0,909 \\
\hline Manga & 3,566 & 1,188 & $3-4-3$ & 0,985 & 0,589 & 1,020 & 0,132 & 0,659 \\
\hline Melancia & 7,938 & 2,645 & $5-2-3$ & 0,974 & 0,595 & 0,755 & 0,076 & 0,512 \\
\hline Melão & 2,505 & 0,835 & $5-2-3$ & 0,989 & 0,844 & 1,403 & 0,605 & 0,886 \\
\hline Pera & 0,959 & 0,320 & $1-5-4$ & 0,998 & 1,006 & 1,417 & 0,595 & 0,932 \\
\hline Pêssego & 0,457 & 0,152 & $2-1-7$ & 0,983 & 0,380 & 3,403 & 0,899 & 1,001 \\
\hline Ameixa (2) & 0,323 & 0,108 & $2-6-2$ & 0,997 & 1,685 & 1,283 & 0,063 & 0,996 \\
\hline Uva & 2,004 & 0,668 & $4-2-4$ & 0,974 & 0,371 & 1,265 & 0,516 & 0,595 \\
\hline Morango & 0,426 & 0,142 & $1-6-3$ & 0,977 & 0,949 & 1,661 & 0,191 & 1,010 \\
\hline C. bovina de prim. & 14,333 & 4,776 & $2-5-3$ & 0,987 & 0,586 & 0,828 & 0,208 & 0,613 \\
\hline Alcatra & 1,796 & 0,599 & $4-2-4$ & 0,956 & 0,931 & 2,265 & 0,207 & 0,842 \\
\hline Filé mignon & 0,354 & 0,118 & $1-2-7$ & 0,979 & 2,060 & 0,403 & 1,378 & 1,302 \\
\hline C. bov. de seg. ${ }^{(1)}$ & 14,272 & 4,756 & $1-6-3$ & 0,979 & 0,213 & 0,319 & $-0,362$ & 0,204 \\
\hline Mortadela & 1,743 & 0,581 & $3-3-4$ & 0,730 & $-0,198$ & 0,644 & $-0,217$ & 0,051 \\
\hline Presunto (2) & 1,179 & 0,393 & $4-3-3$ & 0,996 & 1,041 & 0,902 & 0,162 & 0,711 \\
\hline Frango $^{(1)}$ & 36,261 & 12,084 & $2-7-1$ & 0,968 & 0,078 & 0,128 & $-0,427$ & 0,104 \\
\hline Frango abatido & 17,926 & 5,974 & $5-2-3$ & 0,989 & $-0,200$ & $-0,633$ & $-0,391$ & $-0,233$ \\
\hline Frango congel. (1) & 7,500 & 2,499 & $7-1-2$ & 0,971 & $-0,151$ & $-1,090$ & 0,765 & $-0,151$ \\
\hline Peito de frango & 7,381 & 2,460 & $2-6-2$ & 0,998 & 0,753 & 0,567 & $-0,186$ & 0,504 \\
\hline Coxa de frango & 6,224 & 2,074 & $1-5-4$ & 0,983 & 1,049 & 0,650 & $-0,072$ & 0,418 \\
\hline Asa de frango & 1,831 & 0,610 & $3-5-2$ & 0,977 & 0,631 & 0,280 & $-0,338$ & 0,348 \\
\hline Frango assado & 1,878 & 0,626 & $5-3-2$ & 0,986 & 0,614 & 0,336 & $-0,194$ & 0,431 \\
\hline Ovo de galinha ${ }^{(1)}$ & 9,895 & 3,298 & $2-6-2$ & 0,994 & 0,294 & 0,369 & $-0,054$ & 0,313 \\
\hline Leite de vaca ${ }^{(1)}$ & 71,878 & 23,954 & $3-2-5$ & 0,996 & 0,509 & 0,646 & 0,120 & 0,369 \\
\hline Leite pasteurizado & 60,351 & 20,112 & $6-2-2$ & 0,998 & 0,629 & 0,112 & 0,192 & 0,445 \\
\hline Queijos & 6,427 & 2,142 & $1-7-2$ & 0,998 & 0,723 & 1,042 & 0,090 & 0,834 \\
\hline Queijo prato & 0,801 & 0,267 & $1-6-3$ & 0,992 & 0,106 & 1,383 & 0,197 & 0,897 \\
\hline Mozarela & 2,429 & 0,809 & $3-5-2$ & 0,993 & 1,097 & 0,958 & $-0,268$ & 0,773 \\
\hline Queijo minas & 1,695 & 0,565 & $5-3-2$ & 0,990 & 0,726 & 1,198 & 0,153 & 0,803 \\
\hline Iogurte & 4,664 & 1,554 & $5-2-3$ & 0,996 & 0,500 & 1,131 & 0,346 & 0,606 \\
\hline
\end{tabular}




\begin{tabular}{|c|c|c|c|c|c|c|c|c|}
\hline \multirow{2}{*}{ Tipo de Alimento } & \multicolumn{2}{|c|}{ Consumo anual (kg) } & \multirow{2}{*}{$\begin{array}{l}\text { Esquema de } \\
\text { agrupamento }\end{array}$} & \multirow{2}{*}{$R^{2}$} & \multicolumn{3}{|c|}{ Elasticidade no Estrato } & \multirow{2}{*}{$\begin{array}{c}\text { Elasticidade } \\
\text { Média }\end{array}$} \\
\hline & por família & per capita & & & $\mathrm{I}$ & II & III & \\
\hline Leite condensado & 2,211 & 0,737 & $2-5-3$ & 0,994 & 0,976 & 0,589 & 0,087 & 0,521 \\
\hline Manteiga & 1,053 & 0,351 & $4-5-1$ & 0,991 & 0,314 & 1,238 & $-1,035$ & 0,807 \\
\hline Margarina & 3,678 & 1,226 & $7-2-1$ & 0,972 & 0,293 & $-0,271$ & $-0,853$ & 0,202 \\
\hline Pão francês & 28,481 & 9,491 & $3-5-2$ & 0,995 & 0,249 & 0,028 & $-0,084$ & 0,114 \\
\hline Biscoito $^{(1)}$ & 11,741 & 3,913 & $5-1-4$ & 0,973 & 0,207 & 0,597 & 0,181 & 0,232 \\
\hline Óleo de soja & 13,746 & 4,581 & $7-1-2$ & 0,974 & 0,225 & $-1,290$ & 0,091 & 0,106 \\
\hline Azeite & 0,810 & 0,270 & $2-7-1$ & 0,995 & 1,570 & 1,152 & $-0,024$ & 1,021 \\
\hline Café moído & 7,153 & 2,384 & $5-2-3$ & 0,956 & 0,212 & 0,304 & 0,051 & 0,201 \\
\hline Refrigerantes (1) & 111,454 & 37,142 & $3-4-3$ & 0,996 & 0,495 & 0,593 & 0,339 & 0,497 \\
\hline Cerveja + chopes (1) & 17,739 & 5,912 & $1-6-3$ & 0,992 & 0,367 & 1,343 & 0,213 & 0,878 \\
\hline Vinho & 1,429 & 0,476 & $1-2-7$ & 0,975 & 3,339 & 0,351 & 1,433 & 1,357 \\
\hline Aguardente / cana & 0,437 & 0,146 & $4-4-2$ & 0,847 & 0,519 & 0,270 & $-0,345$ & 0,333 \\
\hline Massa de tomate & 1,105 & 0,368 & $1-6-3$ & 0,972 & 1,379 & 0,359 & $-0,028$ & 0,346 \\
\hline Maionese & 1,180 & 0,393 & $1-6-3$ & 0,993 & 1,692 & 0,608 & 0,124 & 0,523 \\
\hline Sal refinado & 4,051 & 1,350 & $7-2-1$ & 0,751 & 0,112 & $-0,420$ & 0,966 & 0,070 \\
\hline
\end{tabular}

(1) Categoria definida considerando o conjunto de códigos do Tradutor para despesas com alimentos (ver Apêndice 1).

(2) Inclui "nêspera/ameixa japonesa" (código 68.058).

(3) Não inclui "apresuntado" (código 81.036).

\subsection{Diferenças entre áreas rurais e urbanas e entre as grandes regiões do Brasil}

É fundamental lembrar a grande diversidade dentro de todo o território nacional. As elasticidadesrenda para cada produto apresentadas na Tabela 2 são estimativas sintéticas que não revelam essa diversidade. Pode-se, por exemplo, obter estimativas separadas para os residentes em áreas urbanas e para áreas rurais, e para os residentes em cada uma das cinco grandes regiões do país, como mostram a Tabela 3 e a Tabela 4. Cabe deixar claro que selecionamos alguns produtos para ilustrar o problema. Fazer esse tipo de análise para todos os produtos na Tabela 2 fugiria muito do que se considera como um número de páginas razoável para um artigo.

Tabela 3. Consumo anual médio, em quilogramas, por família e per capita, e estimativa da elasticidade-renda de alimentos selecionados, nas áreas urbana e rural do Brasil, com base em dados da POF 2017-2018

\begin{tabular}{|c|c|c|c|c|c|c|c|c|c|}
\hline \multirow{2}{*}{ Alimento } & \multirow{2}{*}{ Área } & \multicolumn{2}{|c|}{ Consumo anual (kg) } & \multirow{2}{*}{$\begin{array}{l}\text { Esquema de } \\
\text { agrupamento }\end{array}$} & \multirow{2}{*}{$R^{2}$} & \multicolumn{3}{|c|}{ Elasticidade no Estrato } & \multirow{2}{*}{ Elasticidade Média } \\
\hline & & por família & per capita & & & I & II & III & \\
\hline \multirow{2}{*}{ Arroz } & Urbana & 53,684 & 18,093 & $2-5-3$ & 0,882 & 0,051 & 0,014 & $-0,297$ & $-0,016$ \\
\hline & Rural & 93,869 & 29,230 & 4-5-1 & 0,952 & 0,261 & $-0,249$ & 0,609 & 0,158 \\
\hline \multirow{2}{*}{$\begin{array}{l}\text { Far. de } \\
\text { Mandioca }\end{array}$} & Urbana & 5,395 & 1,818 & $2-2-6$ & 0,915 & $-0,550$ & $-0,185$ & $-0,364$ & $-0,390$ \\
\hline & Rural & 17,035 & 5,304 & $3-2-5$ & 0,905 & 0,079 & $-1,045$ & $-0,329$ & $-0,122$ \\
\hline \multirow{2}{*}{$\begin{array}{l}\text { Carne bovina } \\
\text { de primeira }\end{array}$} & Urbana & 14,996 & 5,054 & $2-6-2$ & 0,988 & 0,585 & 0,776 & $-0,078$ & 0,611 \\
\hline & Rural & 10,183 & 3,171 & $2-2-6$ & 0,949 & 0,682 & 0,877 & 0,336 & 0,622 \\
\hline \multirow{2}{*}{ Presunto } & Urbana & 1,311 & 0,442 & $2-5-3$ & 0,993 & 0,782 & 0,936 & 0,110 & 0,665 \\
\hline & Rural & 0,354 & 0,110 & $1-7-2$ & 0,981 & 1,379 & 0,965 & 0,448 & 0,945 \\
\hline \multirow{2}{*}{ Frango } & Urbana & 34,454 & 11,612 & $2-7-1$ & 0,966 & 0,082 & 0,153 & $-0,419$ & 0,124 \\
\hline & Rural & 47,573 & 14,814 & $6-3-1$ & 0,980 & 0,237 & 0,057 & $-0,942$ & 0,215 \\
\hline \multirow{2}{*}{$\begin{array}{l}\text { Ovo de } \\
\text { galinha }\end{array}$} & Urbana & 9,424 & 3,176 & $2-6-2$ & 0,990 & 0,172 & 0,406 & $-0,040$ & 0,315 \\
\hline & Rural & 12,845 & 4,000 & $5-4-1$ & 0,982 & 0,669 & 0,333 & $-0,663$ & 0,576 \\
\hline \multirow[t]{2}{*}{ Pão francês } & Urbana & 30,022 & 10,118 & $4-4-2$ & 0,982 & 0,141 & $-0,013$ & $-0,080$ & 0,064 \\
\hline & Rural & 18,828 & 5,863 & $1-1-8$ & 0,972 & 0,013 & 0,674 & 0,069 & 0,197 \\
\hline
\end{tabular}


A elasticidade-renda média para "Arroz" é ligeiramente negativa na área urbana $(-0,016)$, mas é positiva $(0,158)$ na área rural. $\mathrm{O}$ consumo domiciliar médio de arroz é muito maior na área rural do que na urbana e a RFPC na área rural $(\mathrm{R} \$ 949,90)$ é bem menor do que na área urbana ( $\mathrm{R} \$ 1.956,88)$, fazendo que as diferenças entre urbano e rural contribuam para reduzir a elasticidade-renda no Brasil. Verifica-se que a elasticidade estimada para o Brasil $(-0,038)$ fica abaixo do valor negativo da elasticidade na área urbana ${ }^{4}$.

No caso da "Farinha de mandioca", a elasticidade-renda é negativa tanto na área urbana $(-0,390)$ como na área rural $(-0,122)$. Da mesma maneira que no caso do arroz, as diferenças entre urbano e rural contribuem para que a elasticidade-renda no Brasil seja ainda mais baixa $(-0,434)$. Verifica-se que o consumo per capita médio de farinha de mandioca nas áreas rurais do Brasil é 2,9 vezes maior do que nas áreas urbanas. Hoffmann ${ }^{[4]}$ mostra que no início dos anos 2000 essa diferença era de mais de quatro vezes.

Para "Carne bovina de primeira", a elasticidade na área rural $(0,622)$ é semelhante ao valor estimado para a área urbana $(0,611)$ e a relação positiva associada às diferenças entre urbano e rural apenas referenda esses valores, levando a valor semelhante para a elasticidade-renda no Brasil $(0,613)$. Para os demais produtos listados, observa-se que as elasticidades são sempre maiores para área rural vis-à-vis a área urbana.

No caso da "Farinha de mandioca" as diferenças entre regiões são drásticas: enquanto no Sudeste o consumo per capita médio não chega a 600 g, no Nordeste beira os $4 \mathrm{~kg}$. O consumo desse alimento é ainda maior na região Norte, onde o consumo médio per capita supera os $10 \mathrm{~kg}$. Verifica-se que há diferenças regionais substanciais nas estimativas da elasticidaderenda do consumo de farinha de mandioca.
Para carne bovina de primeira, nota-se que a elasticidade-renda do consumo não destoa muito nas cinco regiões, assim como observado para áreas rural e urbana. Para "Presunto" as elasticidades são maiores nas regiões Norte e Nordeste quando comparadas àqueles referentes às regiões Sudeste, Sul e CentroOeste. Para "Frango" observa-se um comportamento contrário, com as elasticidades se mostrando menores nas duas regiões vis-à-vis as demais. No que diz respeito ao consumo de "Ovos de galinha", novamente, não se notam grandes diferenças regionais nas elasticidades.

4 No Apêndice 2 analisa-se com mais profundidade a relação entre a estimativa da elasticidade-renda para o Brasil como um todo e as elasticidades estimadas para partes do País (áreas ou regiões). 
Tabela 4. Consumo anual médio, em quilogramas, por família e per capita, e estimativa da elasticidade-renda, no Brasil e nas suas cinco grandes regiões para quatro alimentos, com base em dados da POF 2017-2018

\begin{tabular}{|c|c|c|c|c|c|c|c|c|c|}
\hline \multirow{2}{*}{ Alimento } & \multirow{2}{*}{ Região } & \multicolumn{2}{|c|}{ Consumo anual (kg) } & \multirow{2}{*}{$\begin{array}{l}\text { Esquema de } \\
\text { agrupamento }\end{array}$} & \multirow{2}{*}{$R^{2}$} & \multicolumn{3}{|c|}{ Elasticidade no Estrato } & \multirow{2}{*}{$\begin{array}{c}\text { Elasticidade } \\
\text { Média }\end{array}$} \\
\hline & & por familia & per capita & & & $\mathrm{I}$ & II & III & \\
\hline \multirow{6}{*}{$\begin{array}{l}\text { Farinha de } \\
\text { mandioca }\end{array}$} & Brasil & 6,998 & 2,332 & $7-1-2$ & 0,963 & $-0,424$ & $-0,907$ & $-0,065$ & $-0,434$ \\
\hline & Norte & 38,221 & 10,790 & $7-1-2$ & 0,569 & $-0,067$ & $-1,570$ & 0,341 & $-0,092$ \\
\hline & Nordeste & 12,222 & 3,868 & $2-1-7$ & 0,969 & 0,054 & 1,064 & $-0,277$ & 0,109 \\
\hline & Sudeste & 1,702 & 0,587 & $7-2-1$ & 0,579 & $-0,064$ & $-0,851$ & 1,791 & $-0,097$ \\
\hline & Sul & 1,138 & 0,409 & $2-6-2$ & 0,814 & 1,725 & 0,190 & $-1,197$ & 0,256 \\
\hline & C. Oeste & 1,762 & 0,595 & $2-1-7$ & 0,488 & $-0,205$ & 0,914 & 0,125 & 0,161 \\
\hline \multirow{6}{*}{$\begin{array}{c}\text { Carne } \\
\text { bovina de } \\
\text { primeira }\end{array}$} & Brasil & 14,333 & 4,776 & $2-5-3$ & 0,987 & 0,586 & 0,828 & 0,208 & 0,613 \\
\hline & Norte & 15,721 & 4,438 & $4-2-4$ & 0,939 & 0,825 & 1,357 & 0,090 & 0,671 \\
\hline & Nordeste & 11,488 & 3,636 & $4-4-2$ & 0,978 & 0,745 & 0,478 & 0,040 & 0,606 \\
\hline & Sudeste & 14,044 & 4,842 & $3-3-4$ & 0,988 & 0,605 & 1,292 & 0,255 & 0,645 \\
\hline & Sul & 15,870 & 5,707 & $2-5-3$ & 0,961 & 0,323 & 0,882 & 0,277 & 0,638 \\
\hline & C. Oeste & 21,099 & 7,121 & $1-8-1$ & 0,915 & $-1,253$ & 0,852 & $-1,400$ & 0,669 \\
\hline \multirow{6}{*}{ Presunto } & Brasil & 1,179 & 0,393 & $4-3-3$ & 0,996 & 1,041 & 0,902 & 0,162 & 0,711 \\
\hline & Norte & 0,423 & 0,120 & $4-3-3$ & 0,953 & 0,778 & 1,479 & 0,019 & 0,829 \\
\hline & Nordeste & 0,691 & 0,219 & $1-6-3$ & 0,988 & 1,405 & 0,973 & $-0,010$ & 0,811 \\
\hline & Sudeste & 1,447 & 0,499 & $2-5-3$ & 0,969 & 0,621 & 1,000 & 0,065 & 0,655 \\
\hline & Sul & 1,649 & 0,593 & $1-7-2$ & 0,981 & 2,608 & 0,606 & 0,292 & 0,578 \\
\hline & C. Oeste & 1,080 & 0,364 & $2-2-6$ & 0,917 & $-0,254$ & 1,516 & 0,370 & 0,555 \\
\hline \multirow{6}{*}{ Frango } & Brasil & 36,261 & 12,084 & $2-7-1$ & 0,968 & 0,078 & 0,128 & $-0,427$ & 0,104 \\
\hline & Norte & 60,403 & 17,052 & $3-1-6$ & 0,517 & $-0,024$ & 1,108 & $-0,112$ & 0,085 \\
\hline & Nordeste & 46,894 & 14,840 & 5-4-1 & 0,994 & 0,269 & $-0,055$ & $-0,387$ & 0,204 \\
\hline & Sudeste & 27,135 & 9,355 & $2-6-2$ & 0,948 & 0,410 & 0,253 & $-0,194$ & 0,232 \\
\hline & Sul & 34,380 & 12,363 & $1-6-3$ & 0,872 & 0,652 & 0,279 & $-0,005$ & 0,227 \\
\hline & C. Oeste & 33,236 & 11,217 & $7-2-1$ & 0,851 & 0,291 & 0,822 & $-1,323$ & 0,356 \\
\hline \multirow{6}{*}{$\begin{array}{l}\text { Ovo de } \\
\text { galinha }\end{array}$} & Brasil & 9,895 & 3,298 & $2-6-2$ & 0,994 & 0,294 & 0,369 & $-0,054$ & 0,313 \\
\hline & Norte & 9,032 & 2,550 & $2-4-4$ & 0,912 & 0,238 & 0,645 & 0,188 & 0,390 \\
\hline & Nordeste & 11,831 & 3,744 & $2-6-2$ & 0,989 & 0,500 & 0,289 & $-0,060$ & 0,353 \\
\hline & Sudeste & 8,541 & 2,945 & $2-5-3$ & 0,985 & 0,170 & 0,541 & 0,038 & 0,355 \\
\hline & Sul & 11,188 & 4,023 & $2-2-6$ & 0,969 & 0,261 & 0,690 & 0,304 & 0,380 \\
\hline & C. Oeste & 9,288 & 3,135 & $1-8-1$ & 0,945 & $-0,255$ & 0,500 & $-1,252$ & 0,408 \\
\hline
\end{tabular}

\section{CONSIDERAÇÕES FINAIS}

Em uma economia mercantil o acesso aos alimentos é condicionado, essencialmente, pela renda. É relevante saber como o consumo de alimentos varia com a renda. Uma maneira de quantificar essa relação é determinar a elasticidade-renda para cada tipo de alimento, o que foi feito aqui utilizando os dados da POF 2017-2018, obtendo-se estimativas atualizadas para um grande número de alimentos. Seria impossível resumir resultados apresentados em mais de uma centena de linhas de tabelas. Assim, são feitos apenas comentários gerais acerca das estimativas apresentadas. De um modo geral, as elasticidades médias estimadas se mostraram coerentes com o esperado.

Observou-se, de modo coerente, que as elasticidades-renda são mais altas para os alimentos mais "nobres" ou relativamente caros. A título de ilustração, pode-se comparar a elasticidade-renda do consumo de "Carne bovina de primeira" $(0,613)$ com a elasticidade-renda do consumo de "Carne bovina de segunda" $(0,204)$, a elasticidade-renda do consumo de "Bananas" (0,511) com a elasticidade-renda do consumo de frutas mais caras como "Ameixas" $(0,996)$ e ainda a elasticidade-renda do consumo de "Leite de vaca" $(0,369)$ com a elasticidade-renda do consumo de "Queijo-prato" (0,897).

Para produtos como "Batata inglesa", "Tomate", "Peito de frango" e "Pão francês", observou-se um decréscimo do valor da elasticidaderenda na passagem do primeiro para o segundo estrato e um novo decréscimo na passagem para o estrato de rendas mais elevadas. Esse tipo de comportamento é tão esperado como aquele observado para "Frutas" de um modo geral, "Carne de boi de primeira", "Queijos", "Refrigerantes" e "Cervejas", em que se observa um crescimento da elasticidade do primeiro para o segundo estrato e um decréscimo do segundo para o terceiro estrato. Esses são casos de produtos cujo consumo só 
cresce mais rapidamente depois de atingido um certo nível de renda.

Para produtos selecionados foram obtidos resultados para áreas urbanas e áreas rurais e para cada uma das cinco grandes regiões do País. Como exemplo ilustrativo, cabe mencionar o caso do arroz: a elasticidade-renda é ligeiramente positiva $(0,041)$ para um estrato mais pobre, mas é levemente negativa $(-0,038)$ no Brasil como um todo; é positiva $(0,158)$ quando se consideram apenas áreas rurais; é praticamente nula $(-0,016)$ nas áreas urbanas e o valor ainda mais baixo $(-0,038)$ no Brasil como um todo se deve ao fato de o consumo per capita médio ser muito maior nas áreas rurais do que nas áreas urbanas, variando no sentido oposto ao da variação nas rendas médias.

Os resultados apresentados neste estudo, somados à literatura existente, permitem acompanhar o comportamento da demanda dos consumidores por alimentos e as mudanças nos padrões alimentares na população nas últimas décadas, podendo auxiliar na formulação de políticas públicas nas áreas de alimentação e nutrição, bem como na elaboração de estratégias de mercado por parte da indústria alimentícia.

\section{Apêndice 1. Os códigos do IBGE e as diferenças na definição das categorias de alimentos}

$\mathrm{Na}$ POF o IBGE usa um código de sete dígitos para identificar os produtos adquiridos pela Unidade de Consumo (família). É usual utilizar apenas os cinco primeiros dígitos, considerando que os dois últimos se referem a detalhes irrelevantes. Para obter as despesas ou o consumo físico de "abacaxi", por exemplo, é necessário coletar as informações para dois códigos: 68.026 (incluindo diversas variedades de abacaxi) e 68.103 (para abacaxi orgânico). Mas há casos mais complicados como, por exemplo, "feijão", com 18 códigos no tradutor de despesas, mesmo sem considerar os produtos orgânicos.

Felizmente o IBGE fornece os tradutores, isto é, arquivos Excel com a lista dos códigos referentes a cada categoria de consumo. Entretanto, a maneira usada pelo IBGE para agrupar o consumo físico não é idêntica à adotada para agrupar as despesas. Assim, há um tradutor das despesas com alimentos e um outro tradutor para aquisição (consumo físico) de alimentos.
É certo que em muitos casos (frutas e produtos hortícolas específicos, por exemplo) a definição é a mesma nesses dois tradutores. $\mathrm{Na}$ Tabela 2 foi usado, em geral, o tradutor para consumo físico. A seguir descrevemos alguns casos de diferenças entre os tradutores.

No tradutor de despesas, o item "açúcar cristal” inclui apenas os códigos 69.002 e 69.087, mas no tradutor de consumo físico inclui também o código 69.068, para "açúcar triturado ou moído".

No tradutor de despesas, o item "pão francês" inclui apenas os códigos 80.001 e 80.116, mas no tradutor de consumo físico inclui também os códigos 80.112 e 80.148, referentes a produtos diet e light.

No tradutor de despesas há um item geral "arroz", ao passo que no tradutor de consumo físico distingue-se "arroz polido" e "arroz não especificado", mas a soma desses dois itens não é igual à categoria "arroz" nas despesas. Em despesas, há um item separado para cereais, leguminosas e oleaginosas orgânicos; assim, os quatro códigos referentes a arroz orgânico (63.043, 63.044, 63.045 e 63.051) não são incluídos em "arroz" (mas são incluídos em "arroz polido" e "arroz não especificado").

No item geral "feijão" em despesas, não são incluídos os quatro códigos $(63.038,63.039,63.040$ e 63.041) referentes a feijões orgânicos. Por outro lado, são incluídos os códigos 63.012 (fava em grão) e 63.026 (feijão guandu), que não são incluídos em nenhum dos itens referentes a feijão no tradutor de consumo físico.

Tanto em despesas como em consumo físico há um item geral para "frutas". Em consumo físico esse item inclui o código 67.140, referente a nigagori ou melão amargo. No tradutor de despesas o código 67.140 é incluído em "legumes e verduras", no subitem "outras". Por outro lado, nas despesas com "frutas" foram incluídos os códigos 68.016 (macadâmia) e 68.025 (cana de açúcar), os quais, corretamente, não foram incluídos no consumo físico de frutas. Cabe ressaltar que essas diferenças têm efeito desprezível no consumo médio anual per capita: 26,414 kg usando o tradutor de consumo físico e $26,416 \mathrm{~kg}$ usando o tradutor de despesas.

No tradutor de consumo físico, no item "carnes bovinas de segunda", além de todos os códigos 
desse item listados no tradutor de despesas, são incluídos os códigos 71.028 (rabada bovina), 71.061 (costela não especificada), 71.071 (brajola) e 71.102 (carne bovina de terceira). Com a definição mais restrita o consumo médio anual per capita é de $4,756 \mathrm{~kg}$ e considerando os códigos listados no tradutor de consumo físico o consumo médio anual per capita de carne bovina de segunda é 4,880 kg.

\section{Apêndice 2. Como um aumento da renda, considerando apenas as elasticidades-renda dentro de cada área ou região, afeta o consumo per capita médio no Brasil}

Ao usar o ajuste da poligonal do logaritmo do consumo per capita em função do logaritmo da renda per capita para estimar a elasticidade-renda do consumo em todo o Brasil, o resultado capta as variações de consumo inter-regionais associadas a diferenças interregionais de renda per capita. Isso acontece, por exemplo, no caso da farinha de mandioca, pois o consumo per capita é muito mais alto nas duas regiões mais pobres (Norte e Nordeste). Neste apêndice mostramos como se pode avaliar a importância dessas diferenças interregionais na estimativa da elasticidade-renda média no País.

Inicialmente vamos deduzir uma expressão que permite avaliar qual seria a elasticidade-renda média nacional considerando apenas os efeitos da renda dentro das regiões. É claro que as mesmas considerações se aplicam às diferenças entres áreas urbanas e áreas rurais.

Seja $N$ a população de pessoas no Brasil e seja $n_{h}$ a população da $b$-ésima área ou região, $\operatorname{com} h=$ $1,2, \ldots, K$. Então

$$
N=\sum_{h=1}^{K} n_{h}
$$

Seja $Q$ o consumo per capita de determinado alimento no Brasil e seja $q_{h}$ o consumo per capita na $b$ ésima área ou região. Verifica-se que

$$
Q=\frac{1}{N} \sum_{1}^{K} n_{h} q_{h}
$$

Seja $Y$ a renda per capita no Brasil e seja $y_{h}$ a renda per capita na $b$-ésima área ou região. Verifica-se que

$$
Y=\frac{1}{N} \sum_{h=1}^{K} n_{h} y_{h}
$$

A elasticidade-renda do produto em cada área ou região é definida como:

$$
\varepsilon_{h}=\frac{d q_{h}}{d y_{h}} \frac{y_{h}}{q_{h}}
$$

Vamos admitir que haja um pequeno aumento proporcional de $100 \theta \%$ na renda em todas as áreas ou regiões. O consumo médio em cada área ou região aumenta $\Delta q_{h}=\theta \varepsilon_{h} q_{h}$, o consumo total em cada área ou região aumenta $n_{h} \theta \varepsilon_{h} q_{h}$ e o consumo médio per capita no Brasil aumenta em

$$
\Delta Q=\frac{\theta}{N} \sum_{h=1}^{K} n_{h} \varepsilon_{h} q_{h}
$$

Definindo a proporção da população nacional que pertence à $h$-ésima região como $\varphi_{h}=\frac{n_{h}}{N}$, a respectiva variação relativa na quantidade consumida é

$$
\frac{\Delta Q}{Q}=\frac{\theta}{Q} \sum_{h=1}^{K} \varphi_{h} \varepsilon_{h} q_{h}
$$

Como a variação relativa na renda foi fixada em $\theta$, a elasticidade-renda do consumo do produto no Brasil decorrente das elasticidades-renda dentro das áreas ou regiões é

$$
\varepsilon_{A}=\frac{1}{Q} \sum_{h=1}^{K} \varphi_{h} \varepsilon_{h} q_{h}
$$

Como $Q=\sum \varphi_{h} q_{h}, \quad$ verifica-se que essa elasticidade-renda é uma média ponderada das elasticidades-renda dentro das áreas ou regiões, com fator de ponderação $\varphi_{h} q_{h}$.

A participação de cada área ou região no consumo total no Brasil é

$$
\omega_{h}=\frac{n_{h} q_{h}}{N Q}
$$


e verifica-se que

$$
\varepsilon_{A}=\sum_{h=1}^{K} \omega_{h} \varepsilon_{h}
$$

É importante notar que essa fórmula foi deduzida pressupondo que a elasticidade-renda de um produto dentro de uma área ou região fosse constante, o que não é verdade quando se ajusta o modelo de poligonal com três segmentos. Usando as elasticidades médias estimadas em lugar de $\varepsilon_{h}$, vamos obter um valor aproximado da mudança no Brasil associada exclusivamente às elasticidades dentro de áreas ou regiões. Essa fórmula foi usada para calcular os valores apresentados na última coluna da Tabela 5 . Na coluna anterior são reproduzidos os valores das elasticidadesrenda já apresentados na Tabela 2.

Tabela 5. Elasticidade-renda total no Brasil e a média ponderada das elasticidades-renda regionais para cinco produtos, conforme dados da POF 2017-2018

\begin{tabular}{|c|c|c|}
\hline \multirow{2}{*}{ Produto } & \multicolumn{2}{|c|}{ Elasticidade-renda no Brasil } \\
\hline & Total & Média das cinco elasticidades regionais \\
\hline Farinha de mandioca & $-0,434$ & 0,012 \\
\hline Frango & 0,104 & 0,213 \\
\hline Ovo de galinha & 0,313 & 0,365 \\
\hline Carnes bovinas de primeira & 0,613 & 0,641 \\
\hline Presunto & 0,711 & 0,659 \\
\hline
\end{tabular}

Quando se estima a elasticidade-renda ajustando a poligonal para os dados de todo o Brasil, o resultado é afetado pelas diferenças regionais no consumo do produto. No caso da farinha de mandioca, o consumo médio é muito mais alto nas duas regiões mais pobres (Norte e Nordeste) do que nas demais. Fazendo uma regressão do logaritmo do consumo médio nas cinco regiões contra o logaritmo da renda per capita ${ }^{5}$, obtém-se um coeficiente de regressão igual a $-3,216$, com $r^{2}=0,951$ e $F=57,88$. Há, portanto, uma forte elasticidade-renda negativa associada às diferenças de consumo médio entre regiões. Isso faz com que a elasticidade-renda da farinha de mandioca no Brasil $(-0,434)$ seja muito mais baixa do que a média ponderada das elasticidades-renda nas regiões $(0,012)$.

No caso do consumo de frango também há relação linear negativa entre o logaritmo do consumo médio regional e o respectivo logaritmo da renda per capita. O coeficiente de regressão, que é uma estimativa da elasticidade-renda inter-regional, é igual a $-0,600$, com $r^{2}=0,812$ e $F=12,93$ (significativo a $5 \%$ ). A elasticidade-renda estimada com os dados para o Brasil
$(0,104)$ é bem mais baixa do que a média ponderada das elasticidades regionais $(0,213)$.

No caso do presunto, por outro lado, o consumo médio regional é mais alto nas regiões com renda per capita maior. Uma regressão ponderada do logaritmo do consumo médio regional contra o logaritmo da renda per capita produz um coeficiente de regressão igual a 1,411, $r^{2}=0,876$ e $F=21,29$. Assim, a elasticidade-renda estimada para o Brasil $(0,711)$ é substancial mente maior do que a média ponderada das elasticidades-renda regionais $(0,659)$.

Para ovo de galinha e para carnes bovinas de primeira a correlação entre o logaritmo do consumo regional e o logaritmo da respectiva renda per capita não se mostra estatisticamente significativa ao nível de $10 \%$.

Os exemplos analisados neste apêndice e os resultados apresentados na Tabela 4 mostram claramente que há diferenças importantes na elasticidade-renda entre regiões e entre áreas rurais e urbanas. Poderíamos, inclusive, obter estimativas distintas para as áreas rurais e urbanas de cada região.

${ }^{5}$ Ponderando cada observação pela participação da região na população do Brasil. 
Isso pode ser relevante, dependendo da finalidade do estudo. É óbvio, entretanto, que fazer tal tipo de análise detalhada para todos os produtos considerados na Tabela 2 fugiria aos limites de um artigo.

\section{REFERÊNCIAS}

[1] IBGE. Séries históricas de desemprego e rendimento [Internet]. 2021 [acesso em 2021 mar 23]. Disponível em: https://www.ibge.gov.br/explica/desemprego.php

[2] Hoffmann R. Distribuição da renda domiciliar per capita no Brasil, 2012 a 2019 e 1995 a 2015. IEPE - Casa das Garças, Texto para Discussão n. 59; 2020.

[3] Sen A. Poverty and Famines: An Essay on Entitlement and Deprivation. Oxford: Clarendon Press; 1982.

[4] Hoffmann R. Elasticidades-renda das despesas e do consumo de alimentos no Brasil em 2002-2003. In: Silveira FG, Servo LMS, Menezes T, Piola SG. (Org). Gasto e consumo das famílias brasileiras contemporâneas. Brasília: IPEA; 2007. p. 463-483.

[5] Hoffmann R. Estimativas das elasticidades-renda de várias categorias de despesa e de consumo, especialmente alimentos, no Brasil, com base na POF de 2008-2009. Rev. de Economia Agrícola. 2010;57(2):49-62.

[6] Vaz DV, Hoffmann R. Elasticidade-renda e concentração das despesas com alimentos no Brasil: uma análise dos dados das POF de 2002-2003, 20082009 e 2017-2018. Revista de Economia. 2020;41(75):282-310.

[7] Hoffmann R, Vaz DV. Evolução do padrão de consumo das familias brasileiras entre 2008 e 2017. Instituto de Economia da Unicamp, Texto para Discussão n. 384; 2020.

[8] IBGE. Pesquisa de Orçamentos Familiares 20172018: primeiros resultados. Rio de Janeiro: IBGE; 2019.

[9] Leal D. Crescimento da alimentação fora do domicílio. Segur. Aliment. Nutr. 2010;17(1):123-132.
[10] Louzada MLC et al. Ultra-processed foods and the nutritional dietary profile in Brazil. Rev. Saúde Pública. 2015;49(38).

[11] Martins APB et al. Participação crescente de produtos ultraprocessados na dieta brasileira (19872009). Rev. Saúde Pública. 2013;47(4):656-665.

[12] Bertasso BF. O consumo alimentar dos brasileiros metropolitanos. In: Silveira FG, Servo LMS, Menezes T, Piola SG (Org). Gasto e consumo das famílias brasileiras contemporâneas. Brasilia: IPEA; 2006. p. 213-225.

[13] Bleil SI. O padrão alimentar ocidental: considerações sobre a mudança de hábitos no Brasil. Cadernos de Debate. 1998;VI.

[14] Oliveira FCR, Hoffmann R. Consumo de alimentos orgânicos e de produtos light ou diet no Brasil: fatores condicionantes e elasticidades-renda. Segur. Aliment. Nutr. 2015;22(1):541-557.

[15] Lucchese T, Batalha OM, Lambert JL. Marketing de alimentos e o comportamento do consumo: proposição de uma tipologia do consumidor de produtos light e ou diet. Organizações Rurais \& Agroindustriais. 2006;8(2):227-239.

[16] Hoffmann R. Elasticidades-renda das despesas com alimentos em regiões metropolitanas do Brasil em 1995-96. In: Silveira FG, Servo LMS, Menezes T, Piola SG (Org). Gasto e consumo das famílias brasileiras contemporâneas. Brasília: IPEA; 2006. p. 197-212.

[17] Menezes T et al. O gasto e a demanda das famílias em saúde: uma análise a partir da POF de 2002-2003. In: In: Silveira FG, Servo LMS, Menezes T, Piola SG (Org). Gasto e consumo das famílias brasileiras contemporâneas. Brasilia: IPEA; 2006. p. 313-346.

[18] Schlindwein MM, Kassouf AL. Mudanças no padrão de consumo de alimentos tempo-intensivos e de alimentos poupadores de tempo, por região do Brasil. In: In: Silveira FG, Servo LMS, Menezes T, Piola SG (Org). Gasto e consumo das famílias brasileiras contemporâneas. Brasília: IPEA; 2007. p. 423-462. 